Journal of Clinical Investigation

Vol. 41, No. 11, 1962

\title{
RHEOLOGY OF HUMAN BLOOD. STUDIES ON THE FLOW OF FRESH VENOUS BLOOD AND OF CITRATED BLOOD THROUGH TUBING OF DIAMETERS BETWEEN 0.09 AND $0.20 \mathrm{CM}$
}

\author{
By PAUL DREIZEN *
}

(From the Department of Medicine, New York University College of Medicine, New York, N. Y.)

(Submitted for publication December 11, 1961 ; accepted July 26, 1962)

Numerous studies have demonstrated that the rheological properties of blood are anomalous, in particular, that rate of flow through cylindrical tubing is not related linearly to the imposed gradient in pressure and that the viscosity of blood increases at low rates of flow (1-10). These data, and similar data obtained by means of other viscometric methods (11-13), are characteristic of non-Newtonian flow (14) and necessitate that any study of the rheological properties of blood must examine the dependence of viscosity upon applied shearing stress.

Investigative work on blood is complicated by the finding that the very removal of blood from the vascular system is associated with changes in rheological properties $(1,15-17)$. These changes may be related to factors, including the nature of the boundary surface (18)-modification of plasma-cellular interactions that result from addition of anticoagulants $(1,12,19)$, differences in oxygen-carbon dioxide content (16, 20,21 ), defibrination (15), differences in temperature (9), or surface denaturation of cellular or plasma proteins-or they may be related to structural damage of the cells and other processes that result from the storage of $\operatorname{blood}(9,12$, 19). Many of these problems may be circumvented and data obtained on blood almost in its native state by a procedure first described by Hürthle (15), in which capillary needles were introduced into the carotid arteries of a dog; intra-arterial pressure was measured simultaneously with rate of flow through a calibrated needle; and the viscosity of blood was estimated through use of Poiseuille's equation $(22,23)$. Essentially similar procedures were used by Burton-Opitz (16, 24, 25), Moll (26), and Swank (27) in studies on animals, and by Pirofsky (17)

* Present address: State University of New York, Downstate Medical Center, Brooklyn, New York. in an investigation on human venous blood, in order to estimate the viscosity of blood at single pressure gradients.

The purpose of the present investigation was to examine the rheological properties of human venous blood over a wide range in shearing stress, with a method based on the Hürthle principle. The critical measurements of rates of flow at different pressure gradients were obtained during removal of blood from an antecubital vein of a human subject through a needle and polyethylene tubing the inner walls of which were siliconized. The rheological data on human venous blood were supplemented by similar studies on human blood stored in acid-citrate-dextrose, in order to examine details of the relationship between flow and pressure and the dependence of viscosity on volume concentration of packed cells. Apparatus of dimensions intended to simulate flow through medium-sized veins was used.

\section{METHODS}

Blood stored in acid-citrate-dextrose. Data were obtained on samples of human blood which had been routinely collected at the Blood Bank of Bellevue Hospital and later rejected for transfusion because of positive Mazzini reactions. Samples of blood remained sealed within sterile glass bottles in a refrigerator over periods from one to thirty-two days, until rheological measurements were performed in an air-conditioned room at approximately $25^{\circ} \mathrm{C}$, or in a warm-room at temperatures up to $38^{\circ} \mathrm{C}$.

The apparatus used for experiments on stored blood was essentially identical with that used for investigations on human venous blood, described later. Polyethylene tubing, of length varying from 35 to $80 \mathrm{~cm}$ and diameter from 0.12 to $0.20 \mathrm{~cm}$, was connected to a reservoir of blood by a needle, of length (to the midpoint of the beveled tip) varying from 3.0 to $7.0 \mathrm{~cm}$ and diameter from 0.09 to $0.11 \mathrm{~cm}$. The outflow from the tubing was collected in a graduated cylinder over a timed interval, at a pressure head determined by the difference in height between fluid level in the reservoir and the orifice of the tubing. Mixing of blood was accomplished by manual shaking of the reservoir after each measurement of flow; serial hematocrits and 
rates of flow at an arbitrary pressure were not significantly changed during the course of an experiment. In order to avoid transient effects before steady-state rates of shear had been attained, rates of flow were measured after approximately fifteen seconds of free flow.

For predominantly laminar flow of a Newtonian fluid through a cylindrical tube between two reservoirs, the viscosity is expressed as $(28,29)$

$$
\eta=\frac{\pi R^{4}\left(P-P_{K E}\right) g}{8(L+\lambda) Q},
$$

where $R=$ radius of tube $(\mathrm{cm}), L=$ length of tube $(\mathrm{cm})$, $P_{K E}=$ kinetic energy correction $\left(\mathrm{g} / \mathrm{cm}^{2}\right), \lambda=$ end-correction $(\mathrm{cm})$, and $g=980 \mathrm{~cm} / \mathrm{sec}^{2}$. The pressure is estimated as $P=h d$, where $h=$ difference in height $(\mathrm{cm})$ between fluid levels in the two reservoirs.

The kinetic energy correction, $P_{K E}$, is expressed as $m d Q^{2} / g \pi^{2} R^{4}$, where $m$ is an empirical constant of the order of unity $(28,29)$. During laminar flow of water through needle and tubing assemblies (V.i.), the kinetic energy correction was sensibly negligible, because 1 ) there was no evident deviation in pressure proportional to $Q^{2}$ throughout the range of flow between 3 and $20 \mathrm{~cm}^{3} / \mathrm{min}$; and 2) a crude estimate of $P_{K E}$ from the above expression, for mean radius of $0.065 \mathrm{~cm}$ and $m=1$, was only $0.3 \mathrm{~g} / \mathrm{cm}^{2}$ at a flow rate of $20 \mathrm{~cm}^{3} / \mathrm{min}$, probably within the error of the procedure.

For the apparatus here utilized, the term $\pi R^{4} g / 8(L+\lambda)$ had to be replaced by a complex expression involving the different dimensions and end-corrections (30). Because these factors could not be easily determined to the required accuracy, they were considered as a single term, the calibration constant $H$, whose magnitude was determined by means of Equation 1 from measurements on distilled water flowing through each needle and tubing assembly at known temperature, and consequently known viscosity. The magnitude of the calibration constant did not significantly change over a range in temperature between 20 and $40^{\circ} \mathrm{C}$, and measurements were usually obtained at room temperature. Since rates of flow at arbitrary pressures were unchanged in an experiment in which the flexible tubing was coiled into three loops of 5 -cm diameter, the gentler curvature of polyethylene tubing ordinarily employed did not significantly alter the pattern of laminar flow.

Data on the flow of water through an assembly are shown in Figure 1a. Flow was directly proportional to pressure at rates of flow between 3 and $22 \mathrm{~cm}^{3} / \mathrm{min}$. The calibration constant for an assembly could be readily estimated from measurements within the linear range of the graph of flow as a function of pressure, but the deviations from a straight line drawn through the point of origin required examination.

1) At low rates of flow, a surface tension error resulted from the discharge of fluid from the tubing into air rather than into a fluid reservoir. Since no theoretical formulation of the surface tension correction $P_{S T}$ is available (28-31), its magnitude was determined empirically from measurements with the orifice of tubing, alternately in open air and immersed in a reservoir. In general, $P_{S T}$
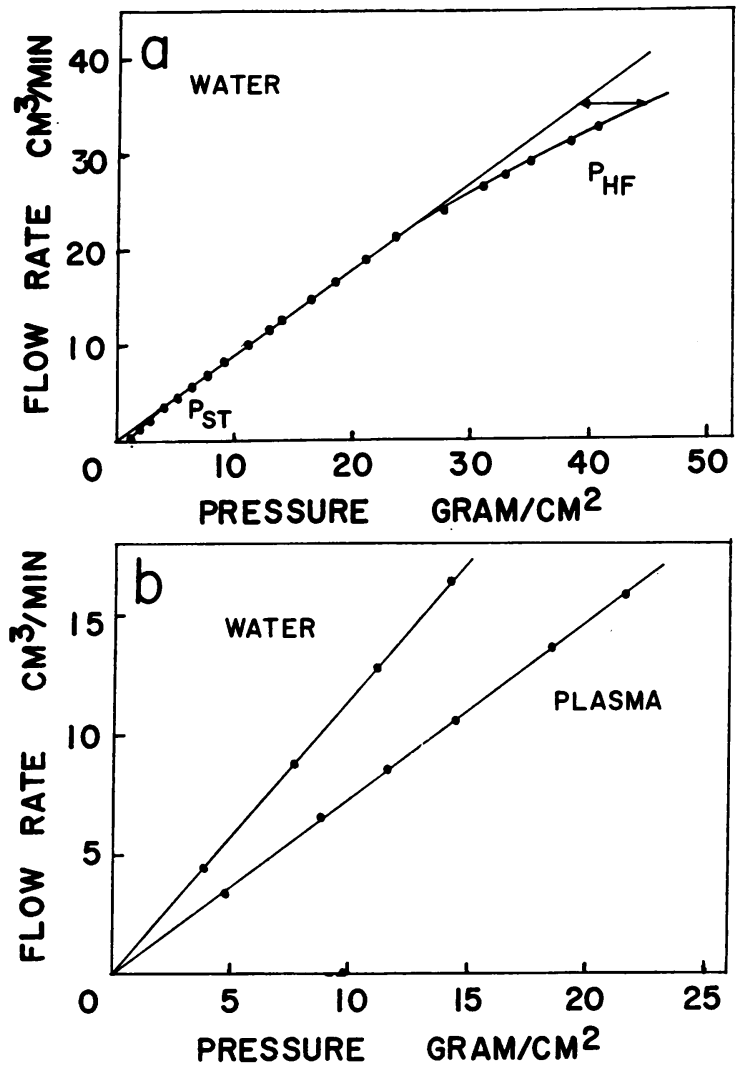

Fig. 1a. Flow Rate in RELATION TO PRESSURE in AN EXPERIMENT WITH WATER. Temperature $24.0^{\circ} \mathrm{C}$. $1 b$. FLOW RATE IN RELATION TO PRESSURE IN AN EXPERIMENT With PLASMa. Temperature $37^{\circ} \mathrm{C}$.

was significantly large at rates of flow less than $3 \mathrm{~cm}^{3} / \mathrm{min}$ for water (Figure 1a) and for blood (Figure 4). A procedure of Haynes and Burton (10), designed to minimize the surface tension error, was not readily applicable to the investigations on human venous blood described below.

2) At high rates of flow, the deviations in pressure $P_{H F}$ were probably due to turbulence. The onset of deviations from linearity occurred at rates of flow of water that depended upon the temperature. For such typical values as $22 \mathrm{~cm}^{3} / \mathrm{min}$ at $28^{\circ} \mathrm{C}$ (Figure 1 a) and $16 \mathrm{~cm}^{3} / \mathrm{min}$ at $38^{\circ} \mathrm{C}$, Reynolds' number was of the order of 500 during flow of water through the needle. For measurements on blood, a comparable change in the graph of $Q$ as a function of $P$ was not noted at rates of flow less than $20 \mathrm{~cm}^{3} / \mathrm{min}$, consistent with the fact that, for flow through a tube at an arbitrary rate, Reynolds' number is significantly higher for water than for blood.

From data obtained during flow through needle and tubing assemblies in a range where the surface tension and high flow errors were negligible, the viscosity of a sample of blood or of plasma at a specific pressure was calculated as

$$
\eta=\frac{H P}{Q} \text {. }
$$


Equation 2 is applicable to non-Newtonian flow, since viscosity is here defined as an experimental variable having explicit dependence on flow and pressure. The coefficient so measured, of ten termed the "apparent viscosity" ( 30 , $5,9,14)$, is to be distinguished from the theoretical constants of specific physical models (see Discussion). The use of Equation 2 to handle rheological data on blood avoids prior reference to a particular model and yields the parameter of principal hemodynamic interest.

Human venous blood. A needle and tubing assembly comprised a needle, inside diameter approximately 0.09 $\mathrm{cm}$ and length (to the midpoint of the beveled tip) $4.3 \pm$ $.07(S D) \mathrm{cm}$, connected to flexible polyethylene tubing, inside diameter approximately $0.13 \mathrm{~cm}$ and length $63.3 \pm$ $.53(S D) \mathrm{cm}$. The inner wall of each assembly was siliconized. ${ }^{1}$

Studies were performed on 42 patients hospitalized on the Third Medical Service of the Bellevue Hospital. A subject remained at bed rest for at least twenty minutes prior to introduction of a needle deep into an antecubital vein of an outstretched arm. Rheological measurements were obtained by the following procedure. The tubing was elevated alongside a meter stick, adjusted with reference to a plumb line, until venous pressure rose to a height $h_{v 1}$. The tubing was lowered so that its orifice was alongside the meter stick at a level $h_{\text {orifice, }}$ and a pressure gradient was imposed; blood flowed through the tubing to be collected over a timed interval in a graduated cylinder. The tubing was again elevated until venous blood rose to a height $h_{v 2}$. The pressure during flow, resulting from venous pressure and hydrostatic pressure, was

$$
P=d\left[\frac{1}{2}\left(h_{v_{1}}+h_{v_{2}}\right)-h_{\text {orifice }}\right],
$$

where $d=$ density of blood $\left(\mathrm{g} / \mathrm{cm}^{3}\right)$, and $P=$ pressure $\left(\mathrm{g} / \mathrm{cm}^{2}\right)$. Successive measurements of flow and of pressure were obtained at different heads of pressure; the range between high and low pressures was covered at least twice. At rates of flow less than approximately $3 \mathrm{~cm}^{3} / \mathrm{min}$, flow was permitted along the walls of the cylinder in order to prevent the formation of drops at the orifice of the tubing.

Preliminary determinations with non-siliconized assemblies had indicated a progressive increase in resistance to flow from about five minutes after venipuncture until complete occlusion of needles occurred from ten to eighteen minutes after venipuncture. Utilization of siliconized needle and tubing assemblies resulted in delay of the onset of this phenomenon until twelve to twenty minutes after venipuncture, thereby permitting at least eight determinations of pressure and flow.

Determinations were routinely performed on subjects who were afebrile. Although the exact temperatures of blood within a vein (32) and within tubing were unknown, the drop in temperature during flow through polyethylene tubing was probably small. In experiments using reser-

${ }^{1}$ Siliconized needle and tubing assemblies were generously supplied by the Sterilon Company, Buffalo, New York. A five per cent solution of Dow-Corning 555 fluid was drawn through each assembly under vacuum pressure; the assembly was autoclaved prior to use. voirs of water at temperatures up to $20^{\circ} \mathrm{C}$ different from room temperature, measurements on the efflux from the tubing at rates of flow approximately $20 \mathrm{~cm}^{3} / \mathrm{min}$ indicated no significant change in temperature from reservoir to orifice.

Samples of blood collected during measurements of flow were heparinized and used for estimation of: density; packed cell volume (centrifugation in two Wintrobe tubes at $3,000 \mathrm{rpm}$ for 30 minutes, without correction for stored plasma); and plasma albumin, globulin, and cholesterol (Chemistry Laboratory of Bellevue Hospital).

A needle and tubing assembly was utilized for a single determination on a subject and discarded after subsequent calibration from measurements on distilled water, as described above. The magnitude of the calibration constant varied from 0.336 to $0.375 \mathrm{~cm}^{4} / \mathrm{sec}^{2}$, with mean 0.356 $\pm 0.007(S D) \mathrm{cm}^{4} / \mathrm{sec}^{2}$. The viscosity of blood at each pressure was calculated by means of Equation 2.

\section{RESULTS}

\section{A. Human venous blood}

Rheological data were obtained on venous blood in 71 determinations on 42 subjects (Table I). Several fluid mechanical problems required consideration.

1) There was no evidence that measurement of flow caused depletion of the venous reservoir with secondary fall in pressure. In data from twenty determinations, selected at random, the mean difference between venous pressures measured before and after 181 measurements of flow was $+0.055 \pm 5.34(S D) \mathrm{mm}$ of blood, a value not significantly different from zero $(t=0.139$, $\mathrm{p}>.50)$. Also, in several experiments in which blood was collected at the maximal pressures permitted by the assemblies, rates of flow (14 to $17 \mathrm{~cm}^{3} / \mathrm{min}$ ) remained constant although the duration of collection was increased from 15 to 45 seconds.

2) The Pitot effect, associated with venous flow away from the orifice of the needle during measurement of pressure, but towards the needle during measurement of flow, was found to be negligible. By a well-known formula of fluid mechanics (33), the head of pressure during measurement of flow exceeded that during measurement of pressure by the value $0.7 \mathrm{v}^{2}$ per $\mathrm{g}$, where $\mathbf{v}=$ average velocity of flow. A rough calculation of this effect indicated that its maximal value was approximately $3 \mathrm{~mm}$ of blood, only 0.5 per cent of the associated pressure head (no. 72).

3) In several experiments in which venous blood was alternately collected with the orifice of 


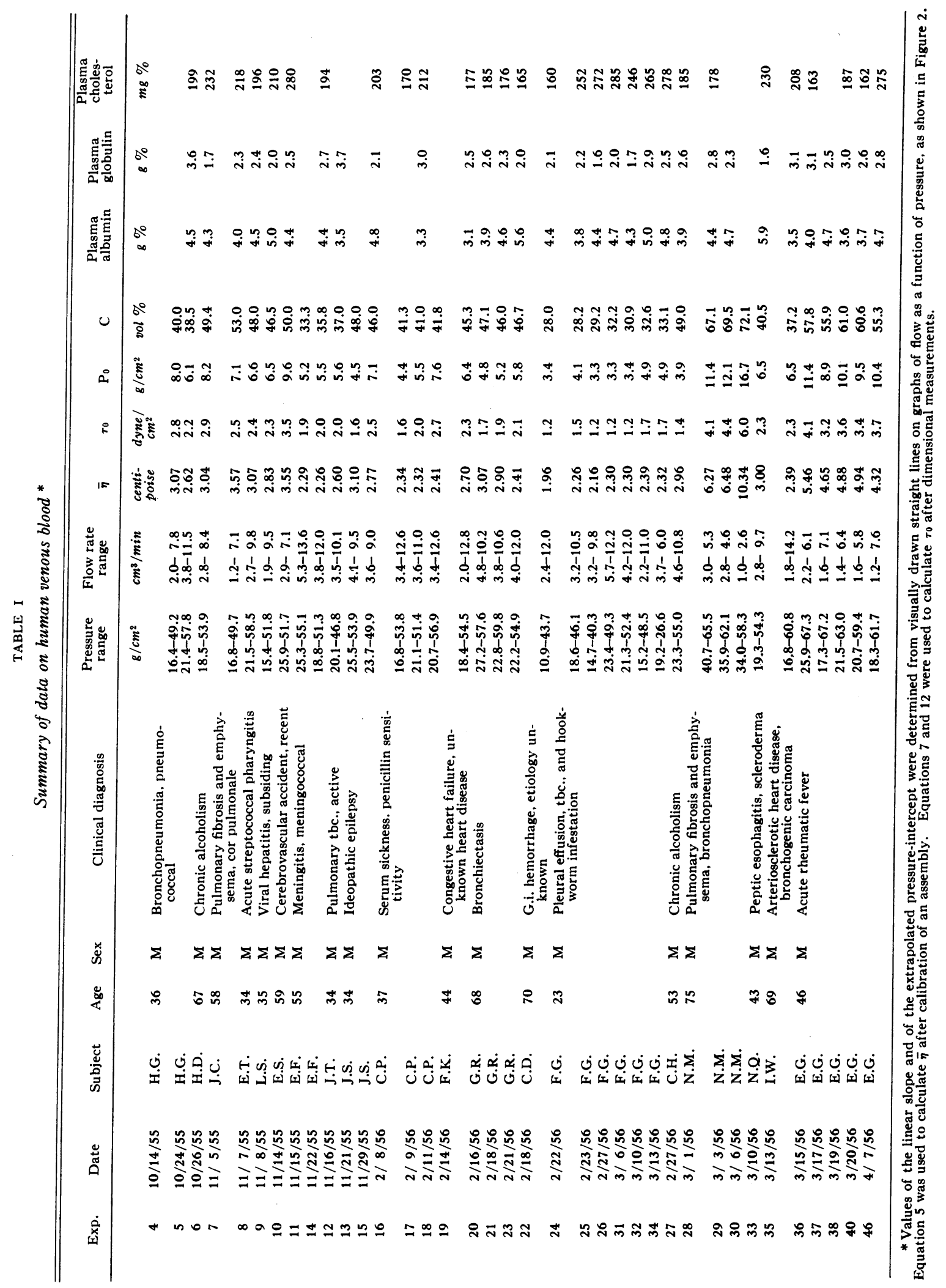




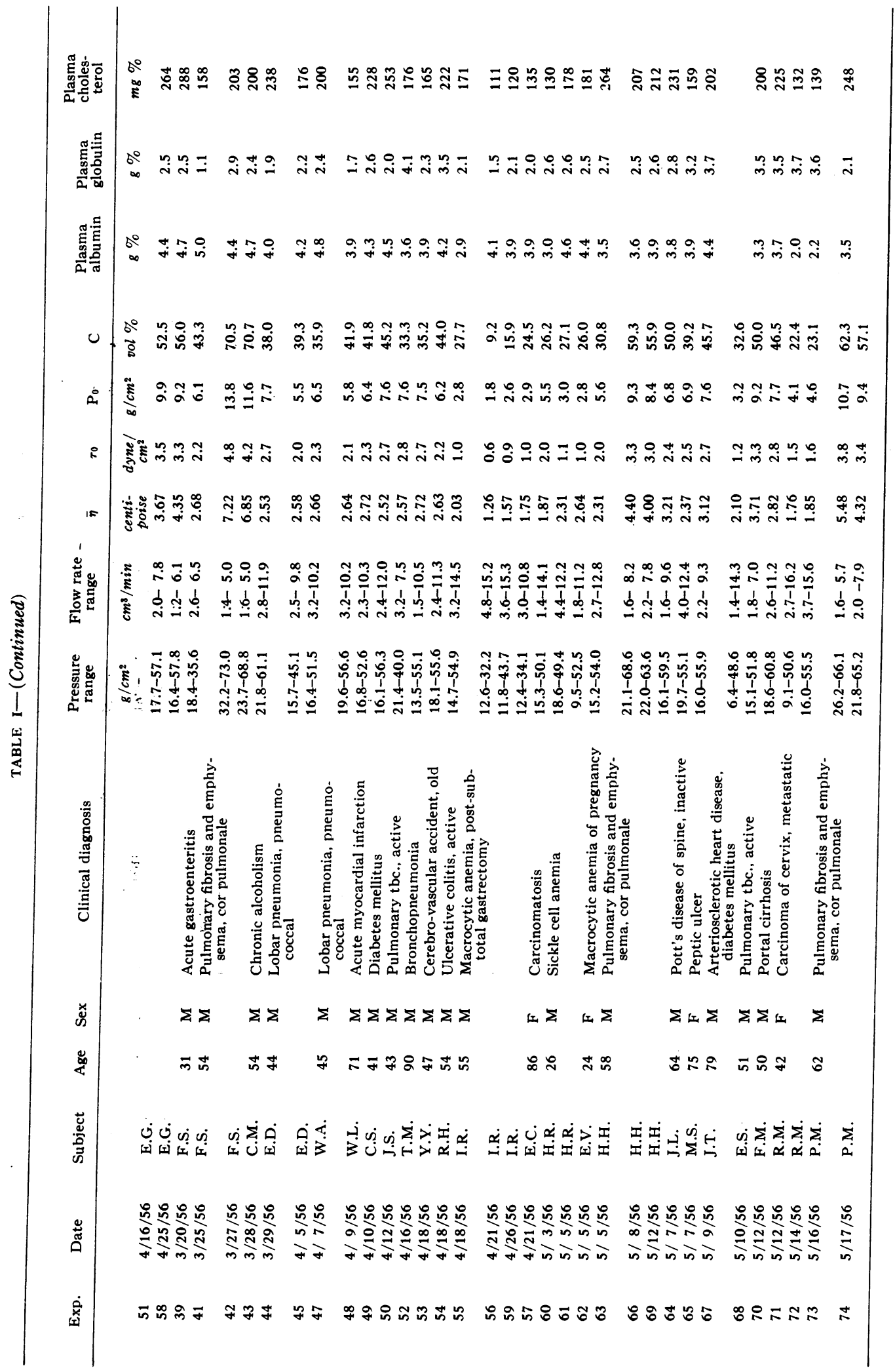


tubing in open air and immersed in blood within a graduated cylinder, the surface tension error was found to be significant at rates of flow less than $3.0 \mathrm{~cm}^{3} / \mathrm{min}$. In all other experiments on venous blood, the formation of discrete drops at low rates of flow was avoided by permitting flow down the surface of the collecting vessel. The surface tension error at low rates of flow was unknown, and data obtained at rates of flow less than $3.0 \mathrm{~cm}^{3} / \mathrm{min}$ were neglected for further calculations, except in three determinations in subjects with polycythemia (nos. 30,41 , and 42 ), where rates of flow were measured over relatively narrow ranges.

In Figure 2 are shown typical data from several determinations. A sensibly linear relationship between flow rate and pressure was noted, and a straight line drawn visually through the data invariably extrapolated to a point on the pressure-axis greater than zero. The magnitude of the linear slope, $d P / d Q$, varied from 2.04 $\mathrm{g}-\mathrm{min} / \mathrm{cm}^{2}$, in subject I. R. with anemia, to 17.5 $\mathrm{g}-\mathrm{min} / \mathrm{cm}^{2}$, in subject N. M. with polycythemia. The magnitude of the pressure intercept $P_{0}$ varied from $1.8 \mathrm{~g} / \mathrm{cm}^{2}$, in subject I. R., to 16.7 $\mathrm{g} / \mathrm{cm}^{2}$, in subject N. M. As indicated in Figure 2 , there was a marked dependence of viscosity upon the pressure gradient, where viscosity increased significantly as pressure was diminished, to an extent related to the volume concentration of packed cells.

These data may be summarized (34) as

$$
Q=\frac{d Q}{d P}\left(P-P_{0}\right), \text { for } P>P_{0},
$$

where $d Q / d P=$ linear slope, and $P_{0}=$ extrapolated pressure-intercept. Then, from Equation 2 ,

$$
\eta=H \frac{d P}{d Q} \frac{P}{P-P_{0}}, \quad \text { for } P>P_{0} .
$$

An asymptotic viscosity $\bar{\eta}$ may be estimated as

$$
\bar{\eta}=H \frac{d P}{d Q} .
$$

Data from 71 determinations, illustrated in Figure 3, indicated that the asymptotic viscosity $\bar{\eta}$ increased nonlinearly with respect to the volume concentration of packed cells, increasing markedly as the concentration exceeded 52 volume per cent. In view of previous data that the fluidity, defined as $\phi=1 / \eta$, may be linearly related to cellular concentration $(35,36)$, the data for asymptotic fluidity, $\bar{\phi}=1 / \bar{\eta}$, were also plotted as a function of concentration. The data in Figure 3 were suggestive of a linear relationship between $\bar{\phi}$ and volume concentration of packed cells, at concentrations of human venous

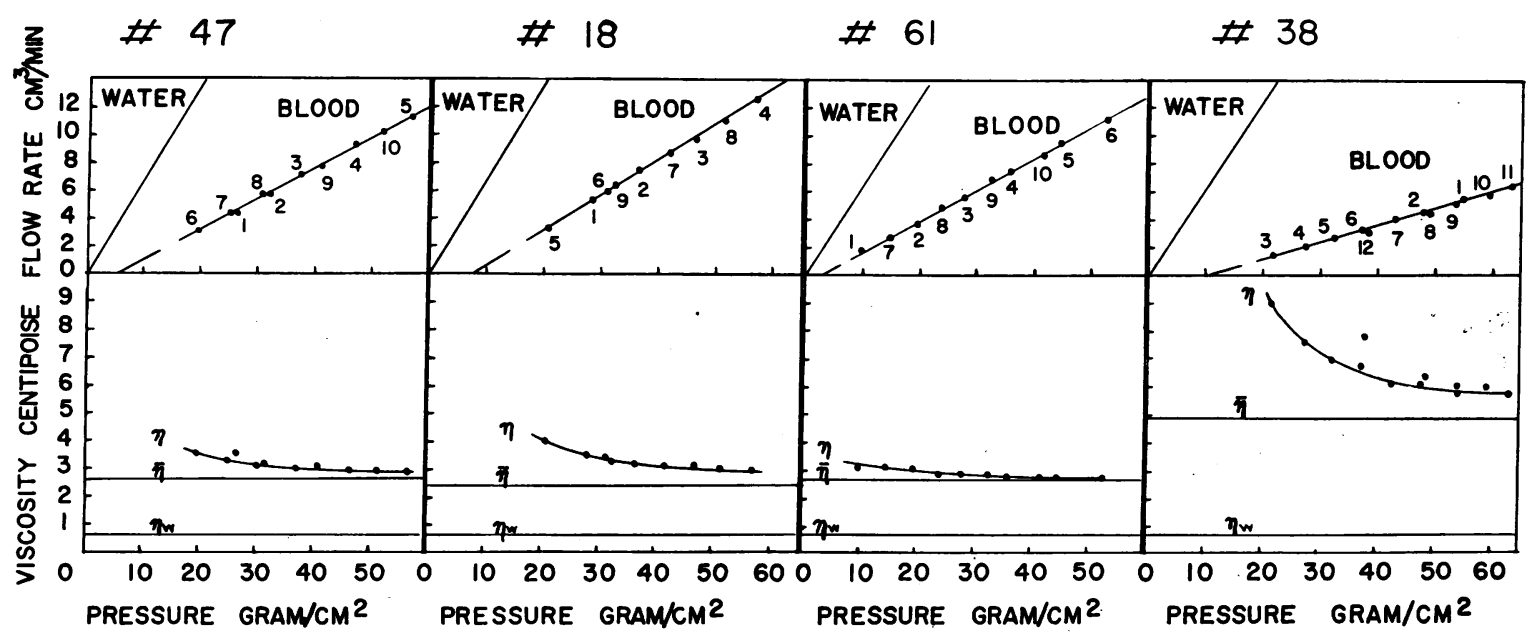

Fig. 2. TYPICAL DATA FROM DETERMINATIONS ON HUMAN VENOUS BLOOD WITH FLOW RATE AND VISCOSITY PLOTTED IN RELATION TO PRESSURE. Numbers adjacent to the points in the graphs of flow as a function of pressure indicate the order in which measurements were obtained. Data on distilled water flowing through the same assemblies are indicated. All lines were drawn visually through the observed points. $\eta=$ observed viscosity of blood; $\bar{\eta}=$ asymptotic viscosity of blood; $\eta_{w}=$ viscosity of water at $37^{\circ} \mathrm{C}$. 


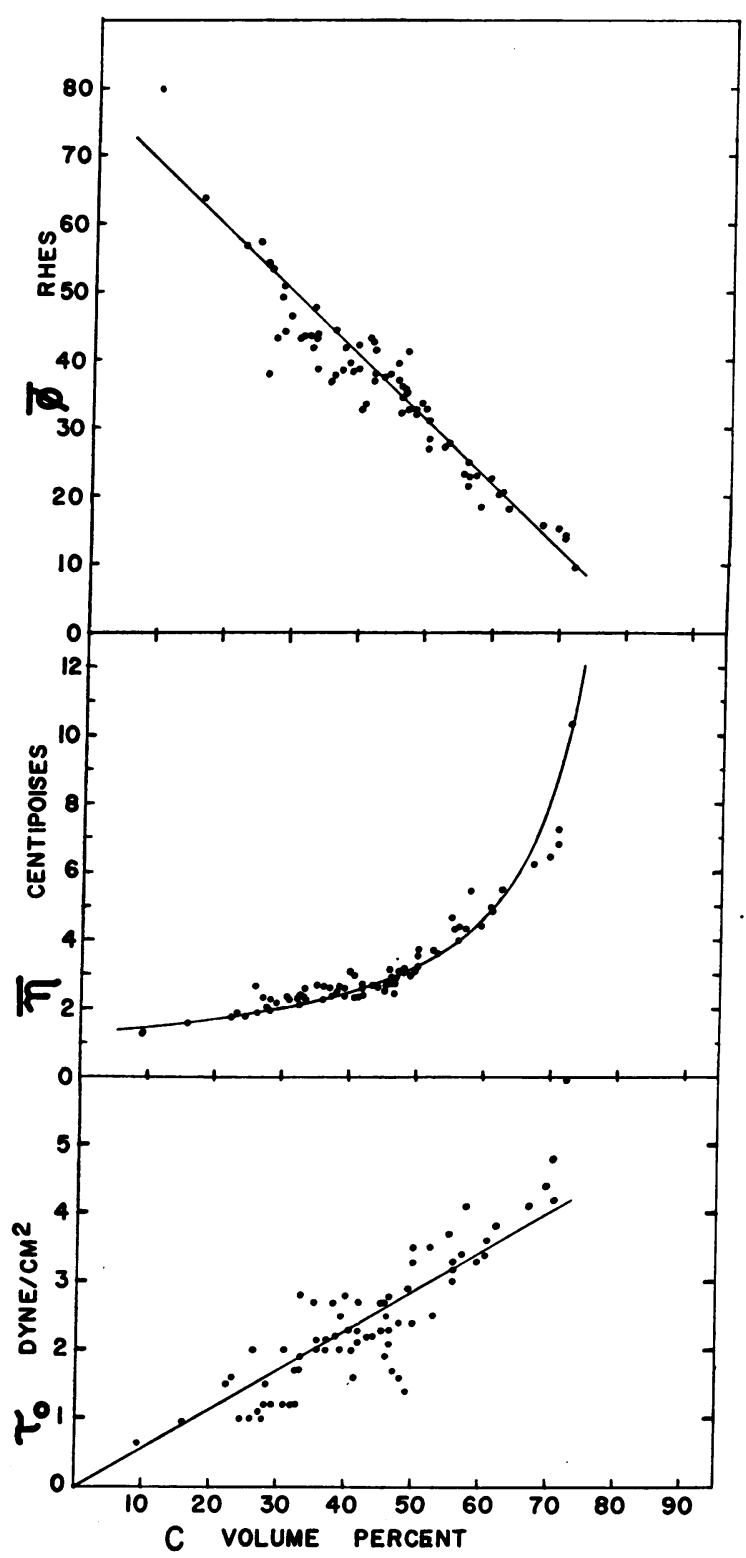

Fig. 3. ASYMPTOTIC FlUIDITy, ASYMPTOTIC viscosity, AND YIELD SHEARING STRESS PLOTTED IN RELATION TO VOLUME CONCENTRATION OF PACKED CELLS FOR DETERMINATIONS ON HUMAN VENOUS BLOOD. The lines for the data on $\bar{\phi}$ and on $\tau_{0}$ were drawn visually, and the reciprocal of the straight line for $\bar{\phi}$ was used to plot the curve for $\bar{\eta}$.

blood between 10 and 70 volume per cent. A rough summary of these data was obtained by means of a visibly fit straight line (Figure 2), described as

$$
\bar{\eta}=\frac{1.29}{1-1.21 C}
$$

where $C=$ volume concentration of packed cells, expressed as a number between 0 and $1 .^{2}$

Examination of Table I indicates that the magnitude of $\bar{\eta}$ was higher than predicted by Equation 6 in several subjects: in Subject H. R. with sickle-cell anemia, one and three days after sicklecell crisis; in Subject E.G. with acute rheumatic fever, during the first week of therapy with salicylates and prednisone; and in several subjects (H.G., E.F., F.G., E.D.), early in the course of acute infectious diseases. Examination of data for fifteen subjects in whom measurements were repeated on different days indicated a good degree of reproducibility, but changes in volume concentration of packed cells and in plasma constituents on serial determinations precluded meaningful statistical analysis of the data.

The magnitude of the extrapolated presssureintercept $P_{0}$ was also dependent upon the volume concentration of packed cells. For reasons which are indicated in the Discussion, the data are plotted in Figure 3 as the yield shearing stress,

$$
\tau_{0}=\frac{3 \bar{R} g P_{0}}{8\left(L_{T}+L_{N}\right)},
$$

where $\tau_{0}=$ yield shearing stress (dynes $/ \mathrm{cm}^{2}$ ), and $\bar{R}=$ mean radius as calculated by Equation 12. The yield shearing stress, ranging from 0.6 to 6.0 dynes $/ \mathrm{cm}^{2}$, was approximately 2.5 dynes/ $\mathrm{cm}^{2}$ at a concentration of 45 volume per cent. The yield shearing stress was roughly proportional to the volume concentration of packed cells, and a straight line was visually drawn

${ }^{2}$ On statistical analysis of the data by the method of least squares, the equation of regression was

$$
\frac{1}{\bar{\eta}}=0.737-.870 \mathrm{C} \text {. }
$$

The standard errors of estimate were 0.0107 for the concentration-intercept, and 0.0239 for the slope. The coefficient of correlation was -.975 . The equation of regression may be rewritten, in conformity with Equation 6 , as

$$
\bar{\eta}=\frac{1.36}{1-1.18( \pm .032 S E) C} .
$$

Since the least squares calculation strongly weighted points where subjects with clinical diseases had elevated values of plasma viscosity $(37,38)$, the statistical analysis was not utilized in preference to the visual plot. 
through the data in Figure $3 .^{3}$ A considerable scatter about any summarizing line may have been related to such factors as experimental error, a difference in bore between needle and tubing, or a marked dependence of $\tau_{0}$ on other variables besides cellular concentration. Examination of Table I indicates a fair degree of reproducibility for data obtained on subjects in whom measurements were repeated.

No relationship was noted between either of these two coefficients and plasma albumin, globulin, and cholesterol as determined routinely in the Chemistry Laboratory of Bellevue Hospital.

\section{B. Blood stored in acid-citrate-dextrose}

Studies were performed on human blood stored in acid-citrate-dextrose, under rheological conditions identical with those imposed on human venous blood, in order to obtain more extensive data on the relationship of flow to pressure than was feasible in the experiments on human venous blood and to examine the explicit dependence of rheological properties, in particular $\bar{\eta}$ and $\tau_{0}$, on volume concentration of packed cells.

1. Flow-pressure relationship. Data obtained in an experiment with plasma at a temperature of $37^{\circ} \mathrm{C}$ are shown in Figure $1 b$. Similar results in four other experiments indicated that the flow of plasma, like that of water, was directly proportional to pressure and that viscosity was constant over measured ranges of pressure or flow.

Data from a typical experiment with blood are shown in Figure 4. In this experiment, rates of flow of blood were negligible at pressures less than $10 \mathrm{~g} / \mathrm{cm}^{2}$. At pressures from 10 to 20 $\mathrm{g} / \mathrm{cm}^{2}$, the observed points fell along a curved line, convex to the pressure-axis. At pressures above $22 \mathrm{~g} / \mathrm{cm}^{2}$, the observed points fell along a straight line, the extension of which intercepted

\footnotetext{
${ }^{3}$ On statistical analysis of these data by the method of least squares, the equation of regression was

$$
\tau_{0}=-0.451+6.64 C \text {. }
$$

The standard errors of estimate were 0.453 for the slope and 0.204 for the concentration-intercept (not significantly different from zero at the 99 per cent level). The coefficient of correlation was 0.866 . In stored blood, the dependence of $\tau_{0}$ on $C$ was described by a nonlinear graph which passed through the point of origin, and the statistical analysis above was not further utilized.
}

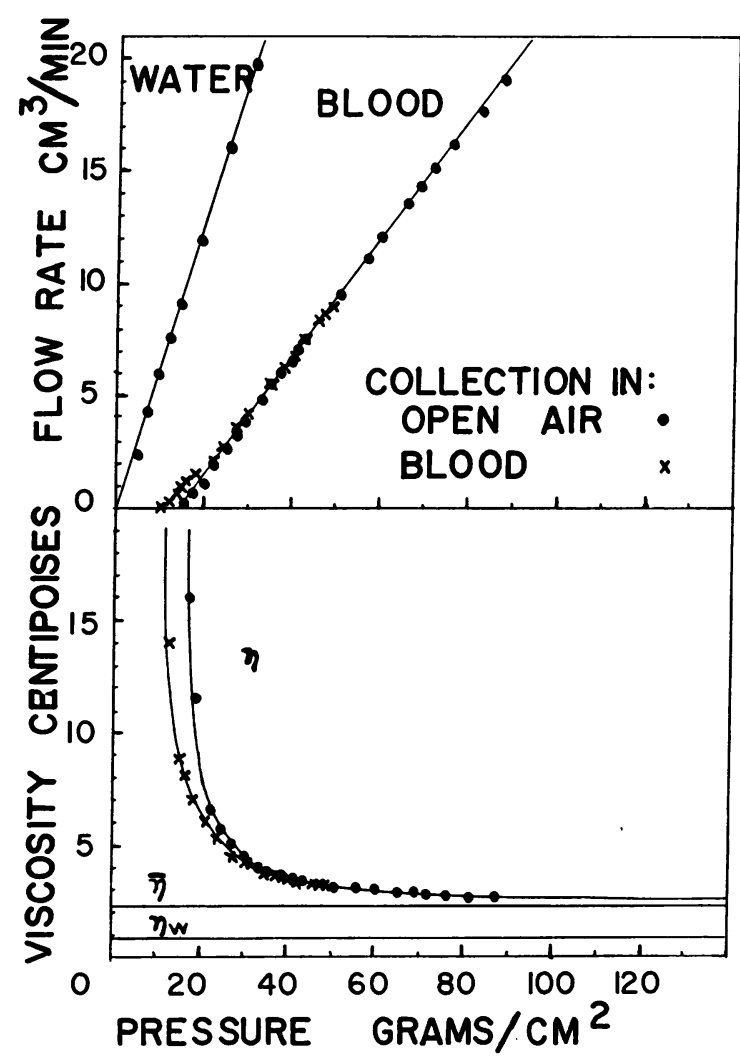

Fig. 4. Flow RATE AND Viscosity in RElation to PRESSURE IN AN EXPERIMENT WITH BLOOD STORED IN aCid-Citrate-DeXtrose. Temperature $27^{\circ}$ C. Packed cells 35 volume per cent.

the pressure-axis at the point $14.2 \mathrm{~g} / \mathrm{cm}^{2}$. The graph of viscosity as a function of pressure exhibited a progressive rise as the pressure gradient was lowered. At rates of flow less than $3 \mathrm{~cm}^{3} /$ min, the surface tension effect was relatively large, of order $8 \mathrm{~g} / \mathrm{cm}^{2}$; but at higher rates of flow, the surface tension correction could be neglected without affecting magnitudes of slope or of pressure-intercept estimated from the linear part of the graph. Furthermore, the marked increase in viscosity at low pressures remained evident, irrespective of the surface tension correction.

In general the experiments on blood stored in acid-citrate-dextrose over periods less than one week, with measurements obtained by means of needle and tubing assemblies at temperatures between 22 and $40^{\circ} \mathrm{C}$, yielded results similar to the data illustrated in Figure 4. Although specific values differed among the separate experi- 
ments, the essential results may be written as follows :

$Q=\left\{\begin{array}{l}\text { nonlinear function of } P, \text { for } P \leqslant P_{0} \\ \frac{d Q}{d P}\left(P-P_{0}\right), \quad \text { for } P>P_{0}\end{array}\right.$,

where $d Q / d P$ and $P_{0}$ are defined as in Equation 3. No extensive investigations were performed to delineate the nonlinear part of the flow-pressure graph because the surface tension correction and time-dependent phenomena related to sedimentation of cells made the apparatus used in the present study unsuitable for measurements at low rates of flow. Hence flow was measured at rates as low as $0.05 \mathrm{~cm}^{3}$ over a period of two minutes but prolonged collection was not done in order to avoid settling of cells and resultant seepage of plasma through the upper part of the cylindrical tubing. The relationship expressed by Equation 8 was found to occur when blood stored up to 32 days was used; however, no systematic measurements were obtained on a sample of blood during "aging."

An experiment was performed in order to test whether the linear slope and the extrapolated pressure-intercept of the flow-pressure graph might be utilized in coefficients that were not dependent upon the exact dimensions of a needle and tubing assembly. Measurements were obtained on blood from a single sample flowing through an assembly whose dimensions were altered by serial shortening of the polyethylene tubing (Table II). As the length of the tubing was diminished from 65 to $35 \mathrm{~cm}$, the slope, $d P / d Q$, diminished from 4.93 to $3.00 \mathrm{~g}-\mathrm{m}: \mathrm{n} / \mathrm{cm}^{5}$; the pressure-intercept, $P_{0}$, diminished from 19.8 to $10.8 \mathrm{~g} / \mathrm{cm}^{2}$. The magnitudes of asymptotic viscosity, $\bar{\eta}$, and of yield shearing stress, $\tau_{0}$, did not change markedly with change in the length of tubing.

2. Viscosity-concentration relationship. The dependence of rheological properties on volume concentration of packed cells that was suggested by the experiments on human venous blood was affected by variations in cellular structure and in plasma constituents of blood among the different subjects. Hence experiments were conducted on samples of blood stored in acid-citrate-dextrose in which all factors except cellular concentration were maintained constant. For each of three units of blood collected three to six days previously, plasma was removed from the bottle containing sedimented cells and further purified by centrifugation at $1,000 \mathrm{rpm}$ for 30 minutes. Rates of flow through a needle and tubing assembly were measured at ten to fifteen different pressures consecutively in the plasma, the concentrated blood, and three or four dilutions of the concentrated blood in the extracted plasma. Measurements were completed within seven hours after bringing a sample of blood to room temperature and breaking its sterility. After calibration of the needle and tubing assembly, values of $\bar{\eta}$ and $\tau_{0}$ were calculated, based upon straight lines visually drawn through graphs of flow as a function of pressure, for each concentration of blood.

In Figure 5 data obtained in one of these experiments are shown. The yield shearing stress, $\tau_{0}$, increased as the volume concentration of packed cells increased, the rate of increase becoming smaller as concentration rose. At arbitrary rates of flow $\left(3,5\right.$, and $\left.10 \mathrm{~cm}^{3} / \mathrm{min}\right)$, the viscosity increased as the volume concentration of packed cells increased, the rate of increase be-

TABLE II

Data from an experiment on blood stored in acid-citrate-dextrose when the length of tubing was successively shortened *

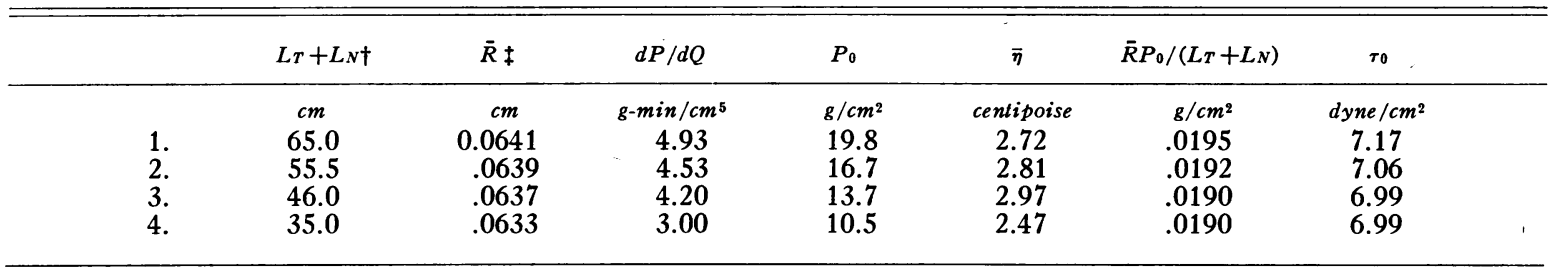

* Measurements were obtained at $35^{\circ} \mathrm{C}$ on a sample of blood that had been collected three days previously. † Other dimensions of the assembly were: length of needle, $L_{N}=3.0 \mathrm{~cm}$; radius of needle, $R_{N}=.045 \mathrm{~cm} ;$ radius of polyethylene tubing, $R_{T}=.065 \mathrm{~cm}$. $L_{T}=$ length of polyethylene tubing.

$\ddagger \bar{R}$ was calculated by Equation 12 . 


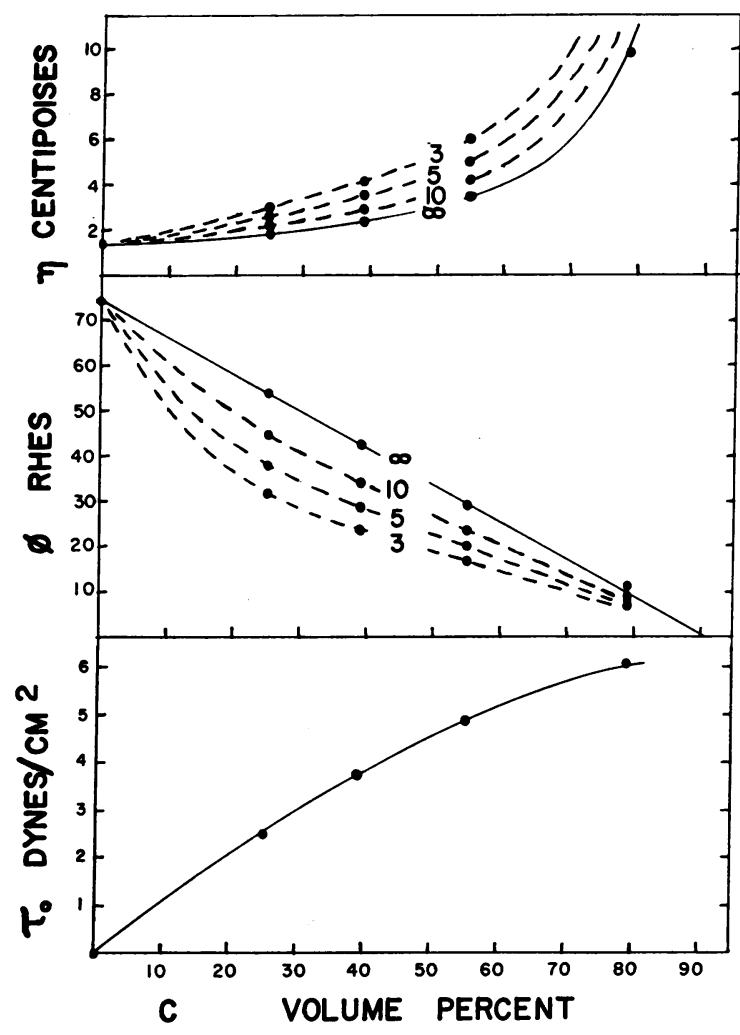

Fig. 5. VISCOSITY, FLUIDITY, AND YIELD SHEARING STRESS PLOTTED IN RELATION TO VOLUME CONCENTRATION OF PACKED CELLS IN AN EXPERIMENT ON BLOOD STORED IN ACID-Citrate-deXtrose. Unit No. 3 in Table III. Data are plotted for viscosity and fluidity at arbitrary rates of flow $\left(3,5\right.$, and $\left.10 \mathrm{~cm}^{3} / \mathrm{min}\right)$, and for asymptotic viscosity and asymptotic fluidity (labeled $\infty$ ). The regression line for the plot of $\bar{\phi}$ (and hence $\bar{\eta}$ ) on $C$ was determined by method of least squares. Other lines were drawn visually.

coming progressively greater as concentration rose. The viscosity was clearly a function of shearing stress under the conditions imposed, for at any one concentration the observed viscosity increased as the rate of flow diminished. On plotting the same data for fluidity as a function of volume concentration of packed cells, a nonlinear dependence of fluidity upon concentration was evident at arbitrary rates of flow. But the asymptotic fluidity was linearly related to volume concentration of packed cells within the examined range of concentration, indicating an inverse linear relationship between $\bar{\eta}$ and $C$.

Experiments with two other units of blood yielded similar data (Table III), which were consistent with the results on human venous blood. Within a range of concentration up to 79 volume per cent, the relationship between asymptotic viscosity and volume concentration of packed cells could be expressed as

$$
\bar{\eta}=\frac{\eta_{p}}{1-\alpha C}
$$

where $\eta_{p}=$ viscosity of plasma and $\alpha=$ constant slope from graph of $\eta_{p} / \bar{\eta}$ as a function of concentration. On statistical analysis of the data from each of the three experiments, the magnitude of $\alpha$ was relatively constant, ranging from 1.10 to 1.12 volume per cent ${ }^{-1}$.

\section{DISCUSSION}

Flow-pressure relationship. Rheological data on the flow of human venous blood and blood stored in acid-citrate-dextrose through tubing 0.10 to $0.20 \mathrm{~cm}$ in diameter and 35 to $80 \mathrm{~cm}$ in length were summarized by Equation 8 . This result agrees with previous data on the flow of blood through tubing of diameter greater than $0.09 \mathrm{~cm}(5,6,8,10,39,40)$. In general, data obtained on the flow of blood through tubing of diameter less than $0.04 \mathrm{~cm}$ have indicated an en-

TABLE III

Data from experiments on blood stored in acid-citrate-dextrose when the volume concentration of packed cells was varied*

\begin{tabular}{cccccc}
\hline \hline $\begin{array}{c}\text { Blood } \\
\text { unit }\end{array}$ & $\begin{array}{c}\text { Duration } \\
\text { of storage }\end{array}$ & $\begin{array}{c}\text { Temper- } \\
\text { ature }\end{array}$ & $\begin{array}{c}\text { Concentrations } \\
\text { examined }\end{array}$ & $\eta_{p} \dagger$ \\
\hline No. & days & ${ }^{\circ} C$ & vol \% & centipoise & vol \% ${ }^{-1}$ \\
1. & 4 & 25. & $0,41,49,61,67$ & 1.13 & $1.12 \pm .039(S E)$ \\
2. & 3 & 26. & $0,12.5,24.5,37$, & 1.19 & $1.11 \pm .020$ \\
3. & 6 & 23.5 & $0,25,39,55,79$ & 1.35 & $1.10 \pm .040$
\end{tabular}

* Dimensions of the assembly were: $L_{N}=7.0 \mathrm{~cm}, R_{N}=.045 \mathrm{~cm}, L_{T}=70.0 \mathrm{~cm}$, and $R_{T}=0.10 \mathrm{~cm}$.

+ The magnitudes of $\eta_{p}$ and of $\alpha$, variables defined by Equation 9 , were calculated by the method of least squares. The observed viscosity at zero-concentration was treated as one of the experimental points for the analysis. 
tirely curvilinear relationship between flow and pressure (7-9).

A linear dependence of flow on pressure with an extrapolated pressure-intercept greater than zero is a relationship that defines a unique pattern of flow, termed plastic flow by Bingham in his original studies on suspensions of clay (34) and of paint (41). Use of this term to describe the rheology of blood has been discussed by Lamport (42) and Bayliss (9). Plastic flow is to be differentiated from viscous flow, where $Q$ is directly proportional to $P$, and from other forms of non-Newtonian flow, where $Q$ is a nonlinear function of $P$ (14). Substances which exhibit plastic flow over a specific range of shearing stress in cylindrical tubing may have other rheological properties outside this range, or in vessels of different shape or dimensions $(43,44)$. Hence the concept of plastic flow is best considered as a useful phenomenological description, the exact physical significance of which is presently unknown.

A widely accepted theoretical model, termed the Bingham model (45), for the phenomenon of plastic flow is one in which a velocity gradient, $\partial v_{i} / \partial x_{j}$, does not occur until the shearing stress, $\tau_{i j}$, exceeds a yield value, $\tau_{0}$, above which the velocity gradient is proportional to shearing stress (46). That is,

$$
\tau_{i j}=\tau_{0}-\frac{\partial v_{i}}{\partial x_{j}} \eta^{\prime}
$$

With this hypothesis and the boundary condition that the velocity of flow at the wall of a vessel is zero, a general expression for flow through cylindrical tubing was developed by Buckingham $(47,48,45)$, and may be written as

$$
Q=\frac{\pi R^{4}}{8 L \eta^{\prime}}\left\{P-\frac{8 L \tau_{0}}{3 R}+\frac{16 L^{4} \tau_{0}^{4}}{3 R^{4} P^{3}}\right\},
$$

where the terms are defined as previously. ${ }^{4}$

The physical significance of the Buckingham equation is illustrated in Figure 6, where $Q$ was plotted as a function of $P$. The first two bracketed terms of Equation 11 describe a straight line which intercepts the pressure-axis at a point $P_{0}=8 L \tau_{0} / 3 R$. The third term of Equation 11

${ }^{4}$ The coefficent of viscosity, $\eta^{\prime}$, for plastic flow was termed plasticity by Bingham (28), but this notation is not generally used. For Equations 10 to $19, P$ is to be understood as pressure having units of dynes $/ \mathrm{cm}^{2}$.

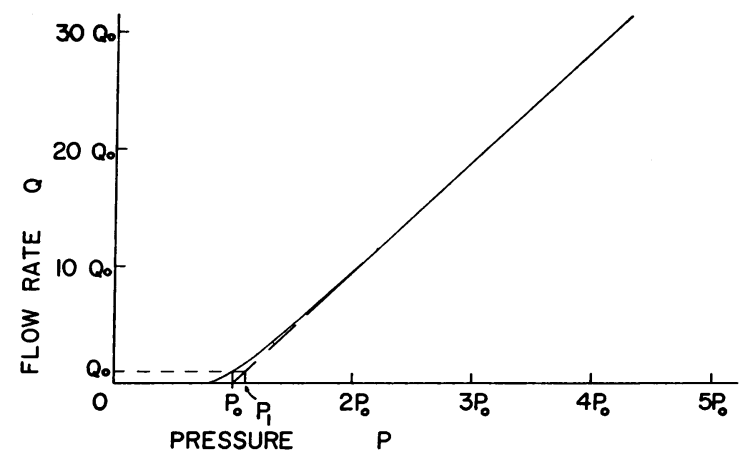

Fig. 6. ThE BUckingham EQUation. The straight line is based upon the first two bracketed terms of Equation 11; the curved line includes the third term of Equation 11. At low rates of flow, the equation breaks down as a useful approximation.

represents a nonlinear component of flow, which becomes negligible as $P$ exceeds $P_{0}$. The Buckingham equation is here considered as a description of rheological properties of a fluid under specified conditions of flow. In particular, other rheological factors, not described by Equation 10, may predominate at low gradients in pressure and be manifest by the occurrence of some flow at all pressures greater than zero.

The applicability of the Buckingham equation to rheological data on blood has been discussed by Bayliss $(9,40)$, who included the terms of Equation 11 in a more general, semiempirical expression, based upon measurements of flow through capillary tubing. The data in the present study do not permit a test of the general expression of Bayliss (40), but do permit a crude test of the Buckingham equation as follows.

First, the parameters $\eta^{\prime}$ and $\tau_{0}$ of Equation 11 may be calculated from the experimental data already described, since $\eta^{\prime}$ corresponds to the asymptotic viscosity $\bar{\eta}$, and $\tau_{0}$ corresponds to the term $3 R P_{0} / 8 L$. For needle and tubing assemblies, a mean radius, $\bar{R}$, was calculated ${ }^{5}$ as:

$$
\frac{L_{N}+L_{T}}{\bar{R}}=\frac{L_{N}}{R_{N}}+\frac{L_{T}}{R_{T}} .
$$

${ }^{5}$ For the needle and tubing assemblies utilized in the investigations on human venous blood, mean radius calculated by the expression

$$
\bar{R}=\frac{L_{N} R_{N}+L_{T} R_{T}}{L_{N}+L_{T}}
$$

was less than 0.8 per cent higher than mean radius calculated by Equation 12 . 
If measurements are obtained in a linear part of the graph of flow as a function of pressure, a specific sample of blood should be characterized by two parameters, $\bar{\eta}$ and $\tau_{0}$, which are independent of tubing dimensions. In the experiment described in Table II, values of $\bar{\eta}$ and of $\tau_{0}$ did not change greatly as the length of tubing was shortened.

Second, it is easily shown from Equation 11 and Figure 6 that

$$
P_{1}-P_{0}=\frac{27}{256} P_{0}
$$

where $Q_{0}=$ actual flow at pressure $P_{0}$, and $P_{1}$ $=$ pressure on straight line corresponding to flow rate $Q_{0}$. With the data shown in Figure 4, one finds that $(27 / 256) P_{0}=1.5 \mathrm{~g} / \mathrm{cm}^{2}$ and that the observed value of $P_{1}-P_{0}$ was approximately $2.7 \mathrm{~g} / \mathrm{cm}^{2}$, representing a fair degree of agreement for these relatively inaccurate data. An unknown surface tension error at low rates of flow precluded further testing of the Buckingham equation for the other data.

The Buckingham equation may then be taken as a first approximation to the rheological properties of blood in needle and tubing assemblies, at gradients in pressure where $d Q / d P$ is constant. The asymptotic viscosity $\bar{\eta}$ and the yield shearing stress $\tau_{0}$ were hence utilized in the present investigation as rheological coefficients of blood. It should be emphasized that the Bingham model is applicable only in a limited range of shearing stress. The procedure here utilized did not allow accurate measurements at low rates of flow, but there is considerable evidence (6-10, $39,40)$ that flow of blood occurs at pressures lower than the cut-off pressure $0.75 P_{0}$ predicted by the Buckingham equation. Also, the imposition of pressures higher than those utilized in the present study introduces other factors, including turbulence and deformation of cells, which would change the observed viscosity at "infinitely" high pressures from that predicted by the asymptotic viscosity.

Nonlinear components of flow observed at low shearing stresses or in narrow tubing are of great interest, for they may be related to a unique boundary phenomenon. It is well-known from microscopic examination of small vessels in living tissue that blood cells closest to the vasc- lar wall move continuously during flow (9). The boundary condition of zero velocity must then be assumed by a thin layer of plasma not containing any cells. Just this condition was also assumed by Buckingham, and a second component of flow, termed the viscous slip, was proposed to occur in substances which exhibit plastic flow (47). The viscous slip was expressed as

$$
Q=\frac{\pi R^{3} P}{2 L} \frac{\epsilon}{\eta_{0}}
$$

where $\epsilon=$ thickness of solvent envelope and $\eta_{0}$ $=$ viscosity of solvent without suspended particles. In a review of the phenomenon of axial drift of blood in capillary tubing, Bayliss suggested that the marginal zone of plasma increases in thickness as the velocity of flow increases (9). Optical measurements by Taylor (49) and Bayliss (50) indicated a marginal zone of diminished density, increasing in thickness as the rate of flow increased; however, a cell-free zone was not evident within the limits of accuracy ( 1 to $5 \mu$ ) of the experimental technique (50). Consequently, Equation 14, or modifications thereof (48), does not satisfy the quantitative requirements of known rheological data.

Although the concept of viscous slip in its present formulation cannot be considered applicable to the flow of blood, the occurrence of some such boundary effect would qualitatively account for the findings that in wide tubing (diameter greater than $0.09 \mathrm{~cm}$ ), the linear component of plastic flow predominates but that in narrower tubing, where $\epsilon / R$ is proportionately large, the nonlinear component of flow becomes appreciable. Furthermore, the occurrence of plastic flow and some phenomenon like viscous slip provides a possible explanation to the results of physiological experiments on the perfusion of hind limbs or intact organs (51), where the relationship of flow to pressure was curvilinear in vascular beds undergoing vasoconstriction (52), but linear at sufficiently high pressure gradients in vascular beds undergoing vasodilatation or augmentation of flow through arteriovenous anastomoses $(5,53)$. Capillary flow, however, cannot be regarded as a homogenous fluid mechanical continuum, and this precludes direct use of the Buckingham formulation as a physically meaningful expression for capillary flow. 
The discussion has been somewhat arbitrary in jumping from a summary of the experimental data, $Q \propto P-P_{0}$, for $P>P_{0}$, to use of the Bingham model. Other formulations than the Buckingham equation have been proposed to describe the flow of blood through tubing. Two of these formulations, which depend upon special plots of the experimental data, illustrate essential difficulties in the interpretation of observed rheological properties.

The first formulation $(7,42,9)$, often termed pseudoplastic flow, is expressed by the equation of Nutting (54),

$$
Q=a P^{n}, \quad n>1,
$$

where $a$ and $n$ are empirical constants determined from a linear plot of $Q$ as a function of $P$ on graph paper with logarithmic coordinates. Equation 15 describes an entirely curvilinear dependence of flow upon pressure, and could be rejected for the present data merely from the observation that $Q \propto P-P_{0}$. One is reasonably concerned, however, over experimental error and might test the data anyway by means of appropriate graphs. As indicated in Figure 7, based upon experimental measurements previously shown on ordinary graph paper, the resulting plots were linear for data on human venous blood (a, no. 18; b, no. 61), but nonlinear for data on stored blood (c, from Figure 4), obtained over greater ranges in flow. Since data may be sensibly linear both on ordinary graph paper and on graph paper with logarithmic coordinates over relatively wide ranges in flow, provided that the constant $n$ of Equation 15 is close to unity, one realizes that empirical curve-fitting must be interpreted with care.

A second formulation, of Scott Blair (55), is based upon an equation proposed by Casson (56), written in notation consistent with Equation 10 as

$$
\sqrt{\tau_{i j}}=k_{0}-k_{1} \sqrt{\frac{\partial v_{i}}{\partial x_{j}}}
$$

where $k_{0}$ and $k_{1}$ are empirical constants. Equation 16 is not a proper tensorial relationship, and is
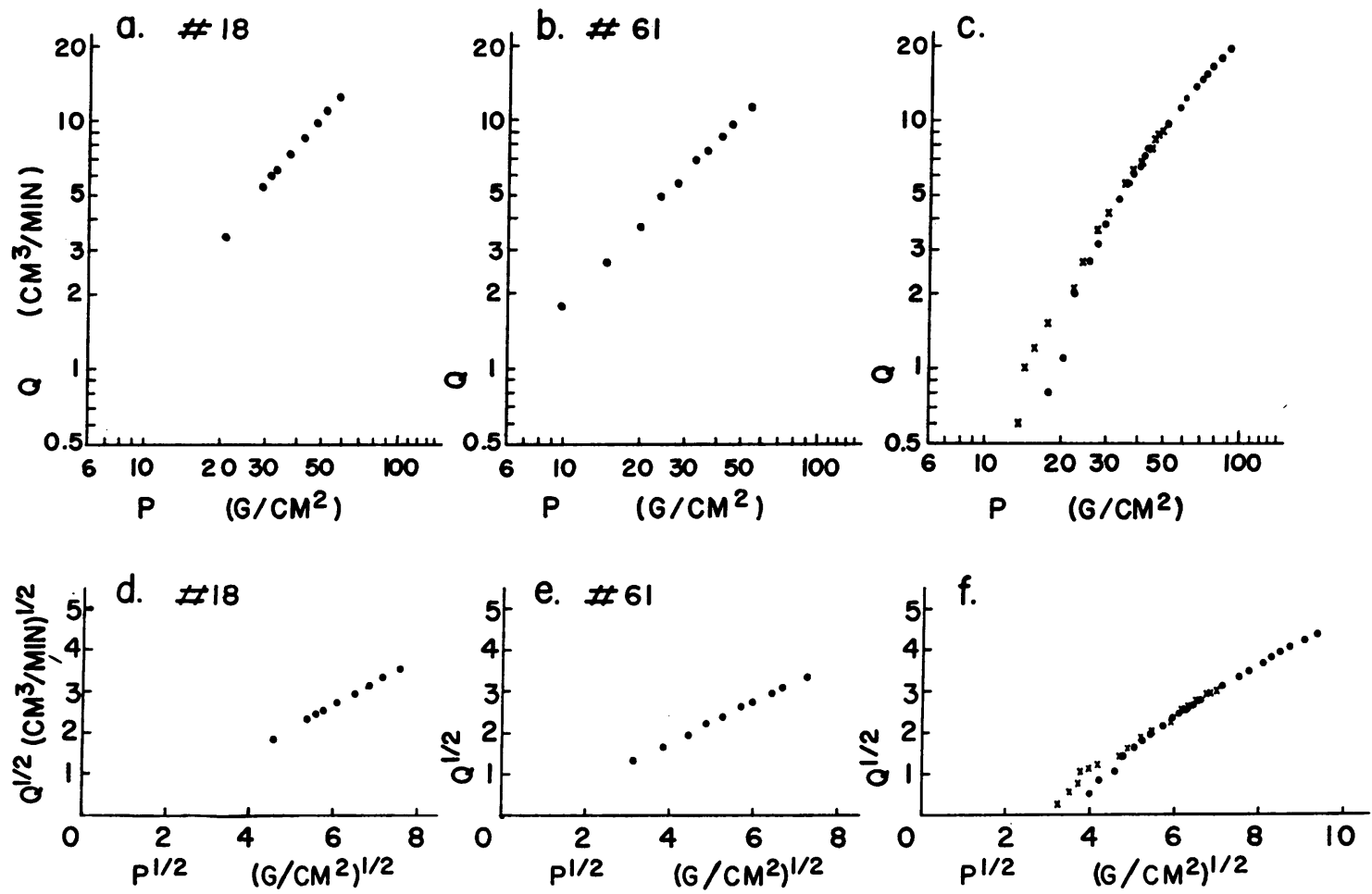

Fig. 7. Special plots of flow rate in relation to pressure. Upper graphs are plotted using logarithmic coordinates (a, no. 18 from Table I; b, no. 61 from Table 1 ; c, data of Figure 4). Lower graphs are plotted with $\sqrt{Q}$ as a function of $\sqrt{P}$ on ordinary graph paper (d, no. 18 from Table $I$; e, no. 61 from Table $I ; f$, data of Figure 4). 
hence unacceptable as a fundamental law of flow (57). Nevertheless, Scott Blair (55) has noted that plots of $\sqrt{\frac{4 Q}{\pi R^{3}}}$ as a function of $\sqrt{\frac{R P}{2 L}}$ are sensibly linear for data on the flow of blood through capillary tubes, and Copley (18) has reported corroboratory findings in glass tubes of diameter from 0.04 to $0.087 \mathrm{~cm}$. Data obtained in the present study have been examined by plotting the explicit variables, $\sqrt{Q}$ as a function of $\sqrt{P}$, on ordinary graph paper. As indicated in Figure 7 ( $d$ and e), data on human venous blood were sensibly linear, but a large extrapolation toward the $\sqrt{P}$-axis was evident. Data on stored blood, previously shown in Figure 4, exhibited a nonlinear plot, but deviations from linearity were not striking (Figure $7 \mathrm{f}$ ). Since the experimental data incurred greatest error at high and at low rates of flow, these data do not permit a definitive empirical test of the Scott Blair formulation.

The experimental data have been expressed in terms of the Buckingham equation, in preference to the Scott Blair formulation. This choice was based on more than empirical grounds, for the two formulations are similar mathematical expressions, depending upon two parameters, which require quite precise data for differentiation. The Scott Blair formulation, without reference to dimensions of tubing or to further modifications at low rates of flow (58), may be written as

$$
\sqrt{Q}=\sqrt{b}\left(\sqrt{P}-\sqrt{P_{2}}\right), \quad \text { for } P>P_{2},
$$

where $b$ and $P_{2}$ are empirical constants. Then,

and

$$
Q=b\left(P-2 \sqrt{P P_{2}}+P_{2}\right)
$$

$$
\frac{d Q}{d P}=b\left(1-\sqrt{\left.P_{2} / P\right)}\right.
$$

Equation 17 describes the absence of flow at pressures less than $P_{2}$. As pressure is increased above $P_{2}$, flow increases slowly and increasingly with respect to pressure; at higher pressures, the slope changes very slightly with respect to pressure. The Scott Blair formulation provides an empirical description of the flow of blood through capillary tubes, possibly not so good as the Buckingham equation for flow through wider tubing of diameter between 0.1 and $0.2 \mathrm{~cm}$.
But an obstacle to immediate acceptance of the Scott Blair formulation is the absence of clear relationship tó current concepts of fluid mechanics. On physical grounds, until definitive data or theoretical developments justify a major change in concept, one prefers use in studies such as the present investigation, of an expression like the Buckingham equation which invokes a minor, although significant modification of the Newtonian law for viscous flow.

Viscosity-concentration relationship. For data obtained on the flow of human venous blood and of blood stored in acid-citrate-dextrose through needle and tubing assemblies, the relationship between asymptotic viscosity and volume concentration of packed cells, at concentrations likely to occur in human subjects, was expressed by Equation 9. The term $\alpha$ is presumably an interaction coefficient which is dependent upon plasma constituents and cellular structure. The data illustrated in Figure 3 may then represent points on a series of overlapping lines, which have different magnitudes of plasma viscosity and of interaction coefficient.

Data as to the dependence of asymptotic viscosity upon packed volume of erythroctyes have been reported by Haynes and Burton (10) on erythrocytes suspended in acid-citrate-dextrose, and by Bayliss (40) on erythrocytes in defibrinated serum, with measurements obtained on tubing over wide ranges of dimension, which included the radial dimensions of needle and tubing assemblies here used. These data revealed curvilinear dependence of both asymptotic viscosity and asymptotic fluidity upon packed volume of erythrocytes. It is possible that differences between the data of Haynes and Burton and of Bayliss and the data reported in the present investigation are related to interactions of fibrinogen or other components of plasma with the erythrocytes, which affect the rheological properties of whole blood. But a possible error related to the surface tension effect can not be excluded in several of the determinations (nos. 30, 41, and 42) on human venous blood.

As indicated in Figure 5, the dependence of observed viscosity upon volume concentration of packed cells was related to the rheological conditions under which measurements were performed. A similar relationship held for the 
rheological properties of human venous blood in needle and tubing assemblies. In order to demonstrate the quantitative dependence of viscosity upon rheological conditions, one may utilize the parameter of wall shearing stress, expressed as

$$
\tau_{\mathrm{wall}}=\frac{P R}{2 L}
$$

for both viscous and plastic flow $(45,48)$. On combining Equations 4, 5, 7, 9, and 18, and rearranging terms, the viscosity of blood may be written as

$$
\eta=\frac{\eta_{p}}{(1-\alpha C)\left(1-\frac{4 \tau_{0}}{3 \tau_{\text {wall }}}\right)},
$$

where this relation holds for flow through needle and tubing assemblies at sufficiently high shearing stress that $\tau_{\mathrm{wall}}>4 \tau_{0} / 3$, or under the identical condition, $P>P_{0}$. With the estimates of $\alpha$ and $\tau_{0}(C)$ for human venous blood, as given by the lines visually drawn through the data in Figure $3, \eta / \eta_{p}$ was plotted as a function of cellular concentration, at arbitrary magnitudes of wall shearing stress that spanned the range in the present study where $d Q / d P$ was observed to be linear (Figure 8).

The data illustrated in Figure 8 may be used to provide a first approximation to the viscosity of blood flowing under laminar conditions through tubing of diameter between 0.09 and $0.20 \mathrm{~cm}$, the upper range perhaps extending higher. Furthermore, as Bayliss (9) has indicated, the dependence of viscosity upon shearing stress accounts for the diversity of results reported in the relationship between viscosity and volume concentration of packed cells, where specific results depended upon unknown shearing stresses $(7,11,17,26,59-63)$. It is interesting that an inverse linear relationship between viscosity and concentration was reported by several investigators who used capillary viscometers with measurements at high gradients in pressure. In fact, Equation 9 was initially proposed by Hess (35), based upon data from several species of animals and from human blood $(64,65)$, as an expression applicable to the viscosity at high shearing stresses. The magnitude of the interaction coefficient was reported to be 1.4 to 1.6 , a result which predicts cessation of flow at some cellular

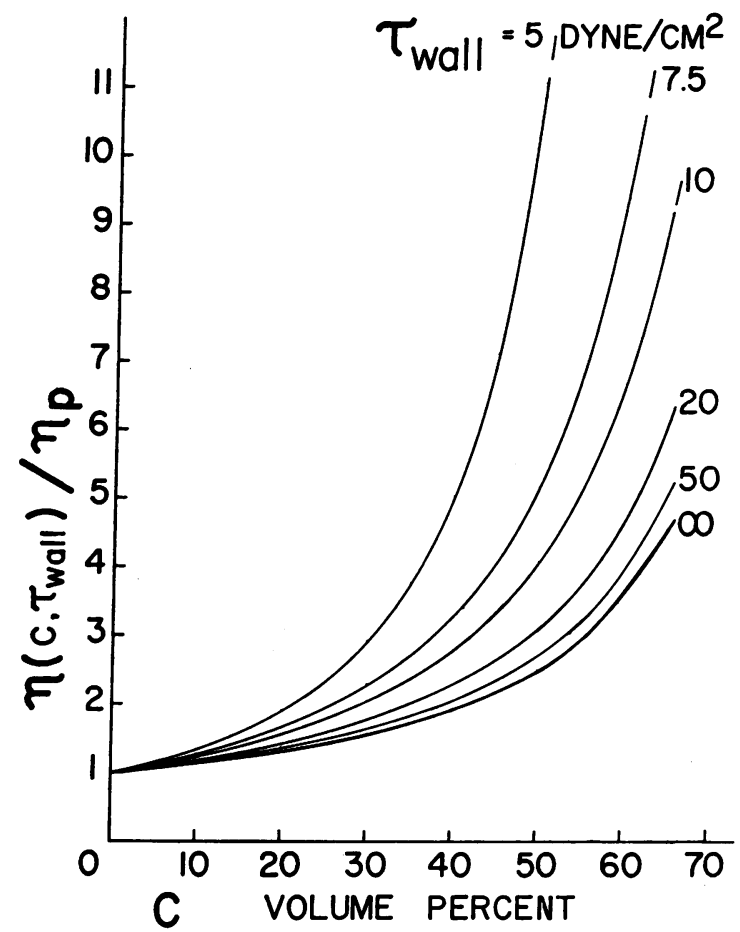

Fig. 8. Viscosity plotted in RELATION to VOLUME CONCENTRATION OF PACKED CELLS, BASED UPON DATA ON human venous Blood. Data are plotted for viscosity at arbitrary wall shearing stresses $(5,7.5,10,20$, and 50 dynes $/ \mathrm{cm}^{2}$ ) and for asymptotic viscosity (labeled $\infty$ ) from calculations using Equation 19 and the magnitudes of $a$ and of $\tau_{0}(\mathrm{C})$ from lines drawn through data in Figure 3.

concentration between 62 and 71 volume per cent, and may have been related to an unknown kinetic energy correction or to transient components of flow unique to the viscometer employed $(66,67)$. An inverse linear relationship between viscosity and hemoglobin concentration was also reported by Bingham and Roepke (36), in a review of data obtained by Blunschy (68) by means of the apparatus of Hess $(66,67)$, on blood from human subjects at concentrations of hemoglobin from 70 to 110 "per cent."

Clinical implications. In arterial flow, where wall shearing stress is roughly 80 dynes $/ \mathrm{cm}^{2}$, the magnitude of viscosity presumably approaches that of $\bar{\eta}$, resulting in minimal resistence to flow. In patients with polycythemia, one might expect some increase of blood viscosity in small veins, where wall shearing stress is roughly 10 dynes $/ \mathrm{cm}^{2}{ }^{6}$ These rheological phenomena are

${ }^{6}$ Crude estimates of wall shearing stress during flow through medium-sized arteries and veins were obtained 
consistent with the clinical observation that venous congestion and thromboses are more evident than phenomena related to low cardiac output in patients with polycythemia vera.

Vasomotor effects may be manifested not only by changes in vascular resistence but by changes in the rheological properties of blood. In particular, if an increase in shearing stress on blood within the arteriolar-capillary bed diminishes its viscosity, then one obtains some rationale for clinical observations that vasodepressor agents in hypertensive disease and pressor agents in shock may be effective although the actual changes in blood pressure seem relatively minor.

The apparatus used in the present investigation simulated flow through medium-sized veins, and one may question whether such data can be considered applicable to other regions of the cardiovascular system. In arterial flow, factors including vascular elasticity, pulsatile flow, local turbulence, and perhaps deformation of cells render uncertain any quantitative interpretation

from data on the dog, described by Green (69). These estimates differ somewhat from previously reported calculations (10).

With Green's estimates of vascular dimensions and pressure gradients, wall shearing stress was calculated by Equation 18 to be $10-15$ dynes $/ \mathrm{cm}^{2}$ in the venae cavae, large veins, medium venous branches, and terminal veins.

A similar calculation was not done for arterial flow because of such phenomena as vascular elasticity, pulsatile flow, periodic changes in radius, turbulence, and stationary waves. Instead, arterial $\tau_{\text {wall }}$ was estimated by utilizing the fact that flow rates and viscosities are similar in magnitude for anatomically comparable arteries and veins, e.g., the femoral artery and the femoral vein. Neglecting higher order corrections to this approximation,

$$
P=\frac{8 L Q \eta}{\pi R^{4}}+\ldots
$$

With Equation 18,

$$
\tau_{\mathrm{wall}}=\frac{4 Q \eta}{\pi R^{3}}+\ldots
$$

For anatomically comparable arteries and veins,

$$
\frac{\left(\tau_{\text {wall }}\right)_{\text {artery }}}{\left(\tau_{\text {wall }}\right)_{\text {vein }}}=\left(\frac{R_{\text {vein }}}{R_{\text {artery }}}\right)^{3}+\ldots .
$$

For medium-sized vessels, the radius of the vein is approximately twice that of the artery (69). Hence,

$$
\left(\tau_{\text {wall }}\right)_{\text {artery }} \simeq 8\left(\tau_{\text {wall }}\right)_{\text {vein }},
$$

and a crude estimate of arterial $\tau_{\text {wall }}$ is 80 dynes $/ \mathrm{cm}^{2}$. The actual value presumably varies widely from this estimate during the course of a cardiac cycle. of conventional rheological data; yet straightforward experimental examination of these factors is possible. In capillary flow, the experimental and theoretical problems are much more difficult because the fluid mechanical system is essentially one of diverse, deformable objects of dimensions similar to that of the enclosed vessel, with unique solvent and boundary properties. Indeed, rheological studies in which measurements are performed at low shearing stresses in viscometers where the width of the shearing zone is much larger than $10 \mu$ cannot be assumed a priori to simulate ordinary capillary flow.

\section{SUMMARY}

1. A technique was described by means of which rheological measurements of flow at different gradients in pressure were obtained during removal of human venous blood through calibrated needle and tubing assemblies, in 71 determinations on 42 subjects.

2. At sufficiently high pressures, human venous blood and blood stored in acid-citrate-dextrose exhibited plastic flow in tubing of diameter from 0.09 to $0.20 \mathrm{~cm}$.

3. At least two parameters were required to characterize the rheological properties of blood. On the basis of the Buckingham equation, the asymptotic viscosity and the yield shearing stress were utilized as rheological coefficients for blood.

4. The asymptotic viscosity exhibited an inverse linear dependence upon the volume concentration of packed cells, with an interaction coefficient, presumably related to cellular structure and plasma constituents, of approximate magnitude 1.2 volume per cent $\mathrm{t}^{-1}$ in human venous blood.

\section{ACKNOWLEDGMENT}

The author wishes to express his appreciation to Dr. E. IV. Merrill, Department of Chemical Engineering, Massachusetts Institute of Technology, for his comments during the final preparation of the manuscript, and to Dr. $\mathrm{H}$. Lamport, Department of Physiology, Yale University, for numerous suggestions in critical review, especially those in reference to the high flow correction, the use of Equation 13, and the comparisons with the Nutting and the Scott Blair formulations.

\section{REFERENCES}

1. Ewald, C. A. Ueber die Transpiration des Blutes. Arch. Anat. Physiol. (Lpz.) (Physiol. Abteil.) 1877, p. 208. 
2. Hess, W. R. Der Strömungswiderstand des Blutes gegenüber kleinen Durchwerten. Arch. Anat. Physiol. (Lpz.) (Physiol. Abteil.) 1912, p. 197.

3. Rothmann, M. Ist das Poisseuille'sche Gesetz für Suspensionen gültig? Pflügers Arch. ges. Physiol. 1914, 155, 318.

4. Rothlin, E. Viskosimetrische Studien über der Einfluss der Temperatur auf den Strömungswiderstand des Blutes und dessen Komponenten. Pflügers Arch. ges. Physiol. 1920, 179, 195.

5. Whittaker, S. R. F., and Winton, F. R. The apparent viscosity of blood flowing in the isolated hindlimb of the dog, and its variation with corpuscular concentration. J. Physiol. (Lond.) 1933, 78, 339.

6. Müller, A. Abhandlungen zur Mechanik der Flüssigkeiten mit besonderer Berücksightigung der Hämodynamik. II. Strömen in Röhren. Arch. Kreisl.-Forsch. 1941, 8, 245.

7. Suter, H. Strömen des Blutes in Kapillaren; Ergänzungen zu den Abhandlungen zur Mechanik der Flüssigkeiten. Arch. Kreisl.-Forsch. 1941, 8, 283.

8. Kümin, K. Bestimmung des Zähigkeitskoeffizienten $\mu^{\prime}$ für Rinderblut bei Newton'schen Strömungen, in verschieden weiten Röhren und Kapillaren bei physiologischer Temperatur. Freiburg in der Schweiz, Paulusdruskerei, 1949.

9. Bayliss, L. E. Rheology of blood and lymph in Deformation and Flow in Biological Systems by A. Frey-Wyssling. Amsterdam, N. Holland Pub. Co., 1952, p. 355.

10. Haynes, R. H., and Burton, A. C. Role of the nonNewtonian behavior of blood in hemodynamics. Amer. J. Physiol. 1959, 197, 943.

11. Brundage, J. T. Blood and plasma viscosity determined by the method of concentric cylinders. Amer. J. Physiol. 1934, 110, 659.

12. Copley, A. L., Krchma, L. C., and Whitney, M. E. Humoral rheology. I. Viscosity studies and anomalous flow properties of human blood systems with heparin and other anticoagulants. J. gen. Physiol. 1942, 26, 49.

13. Wells, R. E., Jr., and Merrill, E. W. Shear rate dependence of the viscosity of whole blood and plasma. Science 1961, 133, 763.

14. Oldroyd, J. G. Non-Newtonian flow of liquids and solids in Rheology Theory and Applications, F. R. Eirich, Ed. New York, Academic Press, 1956, vol. 1, p. 653 .

15. Hürthle, K. Ueber eine Methode zur Bestimmung der Viscosität des lebenden Blutes und ihre Ergebnisse. Pflügers Arch. ges. Physiol. 1900, $82,415$.

16. Burton-Opitz, R. The viscosity of the blood. J. Amer. med. Ass. 1911, 57, 353.

17. Pirofsky, B. The determination of blood viscosity in man by a method based on Poiseuille's Law. J. clin. Invest. 1953, 32, 292.

18. Copley, A. L. Apparent viscosity and wall adherence of blood systems in Flow Properties of Blood and Other Biological Systems, A. L. Copley and G. Stainsby, Eds. New York, Pergamon Press, 1960, p. 97.

19. Berczeller, L., and Wastl, H. Úber die Viskosität von Blutkörperchensuspensionen. I. Biochem. $\mathrm{Z}$. 1924, 153, 111.

20. Welsh, W. H. Viscosity of the blood. Heart 1911, 3, 118.

21. Langstroth, L. Blood viscosity. I. Conditions affecting the viscosity of blood after withdrawal from the body. J. exp. Med. 1919, 30, 597.

22. Poiseuille, J. L. M. Recherches expérimentales sur le mouvement des liquides dans les tubes de très-petits diamètres. C. R. Acad. Sci. (Paris) 1842, 15, 1167.

23. Poiseuille, J. L. M. Recherches expérimentales sur le mouvement des liquides dans lés tubes de trèspetits diamètres. Mémoires présentés par divers savants à l'Acad. Sci. de l'Inst. de France. 1846, 9, 433, trans. by W. H. Herschel in Rheological Memoirs 1940, 1, 1.

24. Burton-Opitz, R. The effect of changes in temperature upon the viscosity of the "living" blood. J. exp. Med. 1906, 8, 59.

25. Burton-Opitz, R., The effect of intravenous injection of solutions of dextrose upon the viscosity of the blood. J. exp. Med. 1906, 8, 240.

26. Moll, K. Vergleichende Blutuntersuchungen. Viscositäts- und refraktometrische Bestimmungen des Blutes, Plasmas und Serums von Hunden, Ratten, Gänsen und Enten und vergleichend im menschlichen Blut nebst Hämoglobinbestimmungen. Pflügers Arch. ges. Physiol. 1943, 247, 74.

27. Swank, R. L. Effect of high fat feedings on viscosity of the blood. Science 1954, 120, 427.

28. Bingham, E. C. Fluidity and Plasticity. New York, McGraw-Hill, 1922.

29. Merrington, A. C. Viscometry. New York, Longmans, Green, 1949.

30. Barr, G. A Monograph of Viscometry. London, Oxford University Press, 1931.

31. Oka, S. The principles of rheometry in Rheology Theory and Applications, F. R. Eirich, Ed. New York, Academic Press, 1960, vol. 3, p. 18.

32. Eichna, L. W., Berger, A. R., Rader, B., and Becker, W. H. Comparison of intracardiac and intravascular temperatures with rectal temperatures in man. J. clin. Invest. 1951, 30, 353.

33. Vennard, J. K. Elementary Fluid Mechanics, 4th ed. New York, John Wiley and Sons, 1961.

34. Bingham, E. C. An investigation of the laws of plastic flow. U. S. Bureau of Standards scientific paper no. 278., June 5, 1916.

35. Hess, W. R. Beitrag zur Theorie der Viskosität heterogener Systeme. Kolloidzschr. 1920, 27, 1.

36. Bingham, E. C., and Roepke, R. R. The rheology of the blood. IV. The fluidity of whole blood at $37^{\circ}$ C. J. gen. Physiol. 1944, 28, 131. 
37. Cowan, I. C., and Harkness, J. The plasma viscosity in rheumatic diseases. Brit. med. J. 1947, 2,686 .

38. Houston, J., Whittington, R. B., Cowan, I. C., and Harkness, J. The plasma viscosity in pulmonary tuberculosis and rheumatic diseases. J. clin. Invest. 1949, 28, 752.

39. Coulter, N. A., Jr., and Pappenheimer, J. R. Development of turbulence in flowing blood. Amer. J. Physiol. 1949, 159, 401.

40. Bayliss, L. E. The anomalous viscosity of blood in Flow Properties of Blood and Other Biological Systems, A. L. Copley and G. Stainsby, Eds. New York, Pergamon Press, 1960, p. 29.

41. Bingham, E. C., and Green, H. Paint, a plastic material and not a viscous liquid; the measurement of its mobility and yield value. Proc. Amer. Soc. Test. Mater. 1919, 19, 640.

42. Lamport, H. Hemodynamics in A Textbook of Physiology, 16th ed., J. F. Fulton, Ed. Philadelphia, W. B. Saunders, 1949, p. 580.

43. Scott Blair, G. W., and Crowther, E. M. The flow of clay pastes through narrow tubes. J. phys. Chem. 1929, 33, 321.

44. Weltmann, R. N. Rheology of pastes and paints in Rheology Theory and Applications, F. R. Eirich, Ed. New York, Academic Press, 1960, vol. 3, p. 189.

45. Bird, R. B., Stewart, W. E., and Lightfoot, E. N. Transport Phenomena. New York, John Wiley and Sons, 1960.

46. Green, H. Further development of the plastometer and its practical application to research and routine problems. Proc. Amer. Soc. Test. Mater. 1920, 20, 451.

47. Buckingham, E. On plastic flow through capillary tubes. Proc. Amer. Soc. Test. Mater. 1921, 21, 1154.

48. Reiner, M. Deformation, Strain and Flow, 2nd ed. London, H. K. Lewis, 1960.

49. Taylor, M. The flow of blood in narrow tubes. II. The axial stream and its formation, as determined by changes in optical density. Aust. J. exp. Biol. med. Sci., 1955, 33, 1.

50. Bayliss, L. E. The axial drift of the red cells when blood flows in a narrow tube. J. Physiol. (Lond.) 1959, 149, 593.

51. Lamport, $H$. The law relating blood flow to perfusion pressure. Fed. Proc. 1949, 8, 90.

52. Green, H. D., Lewis, R. N., Nickerson, N. D., and Heller, A. L. Blood flow, peripheral resistence and vascular tonus, with observations on the re- lationship between blood flow and cutaneous temperature. Amer. J. Physiol. 1944, 141, 518.

53. Pappenheimer, J. R., and Maes, J. P. A quantitative measure of the vasomotor tone in the hindlimb muscles of the dog. Amer. J. Physiol. 1942, 137, 187.

54. Nutting, P. G. A study of elastic viscous deformation. Proc. Amer. Soc. Test. Mater. 1921, 21 , 1162.

55. Scott Blair, G. W. An equation for the flow of blood, plasma and serum through glass capillaries. Nature (Lond.) 1959, 183, 613.

56. Casson, N. A flow equation for pigment-oil suspensions of the printing ink type in Rheology of Disperse Systems, C. C. Mill, Ed. New York, Pergamon Press, 1959, p. 84.

57. Scott Blair, G. W. Flow of blood through narrow tubes. Nature (Lond.) 1960, 186, 708.

58. Reiner, M., and Scott Blair, G. W. The flow of blood through narrow tubes. Nature (Lond.) 1959, 184, 354.

59. Trevan, J. W. The viscosity of blood. Biochem. J. 1918, 12, 60.

60. Nygaard, K. K., Wilder, M., and Berkson, J. The relation between viscosity of the blood and the relative volume of erythrocytes (hematocrit value). Amer. J. Physiol. 1935, 114, 128.

61. Holbrook, A. A., and Watson, M. V. Blood viscosity. With special reference to capillary, arterial (approximate), and venous blood specimens. Amer. J. med. Sci. 1939, 198, 750.

62. Rhiel, J. Vergleichende Blutuntersuchungen. Viscositäts- und refraktometrische Bestimmungen des Blutes Plasmas und Serums von Pferden, Rindern, Schweinen, Schafen, Ziegen und Kaninchen nebst Hämoglobinbestimmungen. Pflügers Arch. ges. Physiol. 1943, 246, 709.

63. Evans, P. Blood viscosity. Lancet 1942, 1, 162.

64. Ulmer, A. Die Bestimmung des Volumens der roten Blutkörperchen auf viskosimetrischem Wege. Zürich, Gebr. Leemann, 1909.

65. Hess, W. R. Blutviskosität und Blutkörperchen. Pflügers Arch. ges. Physiol. 1911, 140, 354.

66. Hess, W. R. Ein neuer Apparat zur Bestimmung der Viskosität des Blutes. Münch. med. Wschr. 1907, 54, 1590.

67. Hess, W. R. Die Viskosimetrie des Blutes. Med. Klin. 1909, 5, 1397.

68. Blunschy, F. Beiträge zur Lehre der Viscosität des Blutes. Einsiedeln, Eberle and Rickenbach, 1908.

69. Green, H. D. Circulation: physical principles in Medical Physics, O. Glasser, Ed. Chicago, The Year Book Publishers, 1944, vol. 1, p. 208. 